\title{
O pandemónio da Gripe Espanhola e as lições sobre o conhecimento científico de prevenção de pandemias
}

\author{
The Spanish flu pandemonium and lessons on scientific knowledge \\ of pandemic prevention
}

Ana Cláudia Coelho, Universidade de Trás-os-Montes e Alto Douro ${ }^{1}$ (accoelho@utad.pt)

Joana Oliveira, Universidade de Trás-os-Montes e Alto Douro (joanamouraoliveira97@gmail.com)

Isilda Rodrigues, Universidade de Trás-os-Montes e Alto Douro (isilda@utad.pt)

Resumo: A Gripe Espanhola, também chamada Pneumónica, foi uma pandemia causada pelo subtipo H1N1 de influenza, que surgiu em 1918, no último ano da I Guerra Mundial. O vírus afetava os pulmões e as vias respiratórias, provocava hemorragia pulmonar e infeção bacteriana secundária. Não se sabe a origem, mas ficou conhecida como Gripe Espanhola, já que os jornais espanhóis reportaram amplamente os efeitos do vírus no país, pois Espanha assumiu uma posição neutra na guerra, não sendo praticada a censura na imprensa. A pandemia disseminou-se por várias partes do mundo e teve três ondas, sendo que a segunda, no outono de 1918, foi responsável por elevadas taxas de morbilidade e mortalidade. No geral resultou em cerca de 500 milhões de infetados por todo o mundo e, em mais de 50 milhões de mortes. Distinguiu-se pela elevada mortalidade em jovens adultos. Portugal foi um país muito afetado. A Gripe Espanhola chegou ao país através do Alentejo, durante os meses de junho e julho de 1918.

Pretendemos, com o presente artigo, refletir sobre como a partir da pandemia de 1918-1919 desenvolveu-se o conhecimento científico na área da saúde pública e como os avanços científicos subsequentes facilitaram o desenvolvimento de medidas

\footnotetext{
${ }^{1}$ Ana Cláudia Coelho (accoelho@utad.pt), Departamento de Ciências Veterinárias, Universidade de Trás-os-Montes e Alto Douro, Vila Real, Portugal; Centro de Ciência Animal e Veterinária CECAV Universidade de Trás-os-Montes e Alto Douro, Vila Real, Portugal

Joana Oliveira (joanamouraoliveira97@gmail.com), Departamento de Ciências Veterinárias, Universidade de Trás-os-Montes e Alto Douro, Vila Real, Portugal

Isilda Rodrigues (isilda@utad.pt), Departamento de Educação e Psicologia, Universidade de Trásos-Montes e Alto Douro, Vila Real, Portugal; Centro de Investigação e Intervenção Educativas, Universidade do Porto, Portugal
} 
preventivas, incluindo vacinas e antivirais. Muitas lições da pandemia de Gripe Espanhola foram aprendidas e contribuíram para a história da ciência na prevenção de outras potenciais pandemias e epidemias que decorreram ou foram prevenidas no século XX e início do século XXI incluindo a pandemia da Covid-19.

Palavras-chave: Gripe Espanhola, Lições, Conhecimento científico, Saúde Pública.

\begin{abstract}
The Spanish Flu, also called Pneumonic, was a pandemic event caused by the H1N1 influenza subtype that emerged in 1918, in the last year of I World War. The virus affected the lungs and airways, causing haemorrhagic pneumonia with secondary bacterial infection. The origin is unknown, but Spanish newspapers widely reported the effects of the virus in the country. As Spain assumed a neutral position in the war, press censorship was not practised. The pandemic spread to various parts of the world in three waves, the second of which, in the fall of 1918, was responsible for the highest rates of morbidity and mortality. Overall, it resulted in about 500 million infected worldwide and more than 50 million deaths. It was distinguished by high mortality in young adults. Portugal was a very affected country. The Spanish Flu entered the country through the Alentejo region, during the months of June and July 1918.

We intend, with this article, to reflect on how from the 1918-1919 pandemic developed knowledge in the field of public health emerged, and subsequent scientific advances facilitated the development of preventive measures, including vaccines and antivirals. Many lessons from the Spanish Flu pandemic have been learned and have contributed to the history of science in preventing other potential pandemics and epidemics that occurred or were prevented in the 20th and early 21st century, including the Covid-19 pandemic.
\end{abstract}

Keywords: Spanish flu, Lessons, Scientific knowledge, Public health.

\title{
Introdução
}

A Gripe Espanhola foi a primeira pandemia de gripe do século XX e também a mais letal. Para evitar alarmar o público, várias autoridades de saúde locais recusaram-se a revelar o número de pessoas afetadas e o número de mortes. Consequentemente, torna-se muito difícil avaliar o real impacto da doença na época (Martini et al., 2019).

A aparência inevitável e imprevisível de novas doenças infeciosas tem sido reconhecida ao longo de milénios. Apesar dos avanços no desenvolvimento científico de medidas nos campos do diagnóstico, da terapêutica e profilaxia (vacinas), vários fatores têm adicionado complexidade à contenção destas doenças, que afetam não só a saúde, mas a estabilidade económica da sociedade (Morens e Fauci, 2013). 
O surgimento de pandemias é influenciado por vários fatores socioeconómicos, ambientais e ecológicos (Jones et al., 2008). Os principais fatores que contribuem para o aparecimento de surtos englobam a adaptação dos microrganismos, suscetibilidade para a infeção, stresse ambiental provocado pela expansão agrícola, alterações climáticas, globalização do mercado de produtos alimentares e industrial, aumento populacional e viagens internacionais (Morse, 2004; McArthur, 2019).

A Gripe Espanhola, também chamada Pneumónica, foi uma pandemia causada pelo subtipo H1N1 de influenza, que surgiu em 1918, no último ano da I Guerra Mundial. Este trabalho consiste numa revisão bibliográfica, onde se pretende contextualizar a pandemia de 1918 em Portugal e no mundo, do ponto de vista social, epidemiológico e clínico e retirar lições que podem ser aprendidas e aplicadas na prevenção de futuras pandemias e epidemias.

A seguir teceremos algumas considerações sobre as principais pandemias que marcaram a história, destacando a Gripe Espanhola e o seu enquadramento no contexto da I Guerra Mundial e em Portugal e, por último, refletiremos sobre a importância do conhecimento adquirido para a prevenção desta e de outras pandemias no futuro.

\section{Principais Pandemias da História da Humanidade}

Ao longo dos tempos surgiram várias epidemias ou pandemias devastadoras que marcaram para sempre a história da humanidade, algumas das quais foram marcos importantes, já que mudaram o rumo da nossa história.

A bactéria Yersinia pestis causou três grandes pandemias desde o século VI, incluindo a Praga do Justiniano e a Peste Negra (Zietz e Dunkelberg, 2004; Raoult et al., 2013). Os ratos, portadores desta bactéria, tiveram um papel importante na disseminação da doença, que se transmitia, principalmente, pela picada da pulga (Zietz e Dunkelberg, 2004). Existem três formas clínicas primárias de infeção por Yersinia pestis em seres humanos: bubónica, pneumónica e septicémica, sendo que a bubónica, caracterizada pelo aumento dos gânglios linfáticos, foi a mais comum (Raoult et al., 2013). Em 541 d.C. surgiu a primeira das três pandemias de Yersinia pestis, denominada Praga do Justiniano (Zietz e Dunkelberg, 2004), que se originou no Norte de África e disseminou-se para a Europa, causando cerca de 100 milhões de mortes (Wagner et al., 2014). Esta pandemia interrompeu a reconquista do Império Romano, marcando a transição do período clássico para o medieval (Raoult et al., 2013; Wagner et al., 2014). A segunda pandemia, conhecida como Peste Negra, iniciou-se em 1347 e disseminou-se através dos Himalaias para o oeste, devastando o mundo ocidental, com a morte de 25 a 30\% da população, originando ou acelerando mudanças políticas, económicas, sociais e culturais (Zietz \& 
Dunkelberg, 2004; Raoult et al., 2013). Por fim, a terceira pandemia de Yersinia pestis, iniciada na província chinesa de Yunnan, por volta de 1855, disseminou-se por todo o mundo, afetando todos os continentes habitados; contudo, teve um efeito menor na perda demográfica (Zietz \& Dunkelberg, 2004).

A pandemia global da gripe de origem suína, causada por uma nova estirpe H1N1, descendente da estirpe que causou a pandemia de gripe de 1918, foi reconhecida pela primeira vez na fronteira entre os Estados Unidos da América e o México, em abril de 2009. Durante um curto período de 2 meses, tornou-se a primeira pandemia do século XXI (Rewar et al., 2015), que resultou numa taxa de mortalidade entre crianças, jovens adultos e mulheres grávidas muito maior do que numa típica época de gripe. A Rede Global de Vigilância da Gripe da Organização Mundial de Saúde detetou, identificou e caracterizou o vírus em tempo útil e monitorizou o curso da pandemia e algumas recomendações, como a melhoria dos protocolos para a partilha de vacinas, foram realizadas (Fineberg, 2014).

O vírus Ébola foi identificado pela primeira vez em 1976, quando ocorreram dois surtos em simultâneo, na República Democrática do Congo, e numa área remota do Sudão (World Health Organization, 2020). A doença pelo vírus Ébola é uma zoonose, o reservatório animal do vírus permanece incerto, mas as últimas evidências sugerem que os morcegos frugívoros (Pteropodidae) podem ser hospedeiros naturais (Murray, 2015; World Health Organization, 2020), e os primatas não humanos são hospedeiros intermediários (Murray, 2015; Coltart et al., 2017). Os humanos são normalmente infetados através do contacto com animais infetados (geralmente após matar, cozinhar ou comer) ou através do contacto com fluidos corporais de humanos infetados (Murray, 2015; World Heath Organization, 2020). Os sintomas de Ébola variam, mas febre, fraqueza, dor muscular, dor de cabeça e de garganta são comummente experienciados no início da doença, e, à medida que a doença progride, desenvolvem vómito e diarreia, erupção cutânea, disfunção renal e hepática e, em alguns casos, hemorragia interna e externa. As taxas de mortalidade variaram de $25 \%$ a $90 \%$ nos surtos existentes (World Health Organization, 2020).

A estirpe Zaire do vírus Ébola causou um surto de 2013-2016, na África Ocidental, maior do que todos os surtos anteriores de Ébola combinados, com 28646 casos e 11323 mortes notificadas. O surto teve início no final de 2013 na Guiné e disseminou-se para vários países, sendo a Serra Leoa e a Libéria os mais afetados. Este surto foi o mais longo e foi o primeiro com propagação transcontinental, atingindo inicialmente a África e depois a Europa e a América do Norte (Coltart et al., 2017). Depois de 23 de março de 2014, a Organização Mundial da Saúde envolveu-se ao ser notificada sobre a extensão do problema. Este surto 
ocorreu devido à falta de informação (evitar contacto com morcegos e primatas não humanos infetados), práticas de saúde pública inadequadas (protocolos de isolamento, implementação de quarentenas e práticas de sepultura inseguras), facilidade de viajar, controlo insuficiente da infeção e educação precária em cuidados de saúde (Murray, 2015). As medidas de controlo de surtos anteriores foram cruciais para a resposta, mas o atraso de implementação das mesmas teve consequências devastadoras. Além disso, alegadamente esta falha resultou na falta de progresso científico, o que significa que foi desperdiçada uma oportunidade para melhorar os resultados de surtos futuros (Coltart et al., 2017).

Esta luta entre a engenhosidade humana e a adaptação microbiana representa um desafio perpétuo devido à capacidade evolutiva de adaptação dos microrganismos infeciosos a novos nichos ecológicos e às pressões humanas direcionadas à sua eliminação, que os tornam altamente adaptáveis (Fauci e Morens, 2012).

\section{A Gripe Espanhola - O Vírus Influenza}

As epidemias de influenza, vulgarmente chamadas gripe, são causadas por vírus de RNA da família Orthomyxoviridae que circulam em humanos e ocorrem de forma cíclica e sazonal, em termos anuais. Desde o século XVI ocorrem a cada 30-40 anos. Resultam em milhões de doentes e hospitalizações, apesar da vacinação intensiva e dos programas de sensibilização que existem atualmente (Krammer et al., 2018). O surgimento do subtipo de influenza H1N1 em 1918, levou a cerca de 50-100 milhões de mortes em todo o mundo e mudou para sempre o curso da história humana (Taubenberger \& Morens, 2008).

Após a Gripe Espanhola, mais três pandemias e várias epidemias de gripe ocorreram no século XX, incluindo o H2N2 em 1957 (Gripe Asiática), o H3N2 em 1968 (Gripe de Hong Kong) e a pandemia H1N1 em 2009 (Gripe A). Em termos epidémicos, a Gripe Russa de 1977, causada pelo H1N1, também levou a alguns surtos a nível mundial e o subtipo H5N1 causou a Gripe Aviária entre 1997 e 2004 (Zou \& Cao, 2020).

Em 1918, acreditava-se que o bacilo de Pfeiffer, atualmente conhecido como Haemophilus influenzae, era o agente etiológico da gripe, visto que era frequentemente isolado dos pacientes. No final do século XIX, para a comunidade científica, a gripe era causada por bactérias como pneumococos, estreptococos ou Haemophilus influenzae. Este último também foi denominado Bacillus influenzae ou bacilo de Pfeiffer, em homenagem a Richard Pfeiffer (1858-1945), que o descreveu durante a epidemia de influenza de 1889-1892 (Bazin, 2011). Em outubro de 1918, Nicolle e Lebailly, cientistas do Instituto Pasteur em Paris, avançaram pela primeira vez a hipótese de que o agente patogénico responsável pela gripe era um agente infecioso de reduzida 
dimensão, um vírus. Os seus efeitos patogénicos aumentavam transitoriamente a pneumonia bacteriana secundária a outras coinfeções como o sarampo e a malária, ou outras comorbilidades como a desnutrição ou a obesidade (Shankse Brundage, 2012; Short et al., 2018). Outros cientistas da época também começaram a suspeitar que as bactérias não eram o verdadeiro agente etiológico da gripe. Um deles foi o investigador americano Richard Edwin Shope (1901-1966), que investigou profundamente a gripe suína em 1920. No entanto, foi apenas em 1932-1933 que os cientistas ingleses Wilson Smith (1897-1965), Sir Christopher Andrewes (1896-1988) e Sir Patrick Laidlaw (18811940), isolaram pela primeira vez o vírus influenza A das secreções nasais de pacientes infetados, demonstrando assim, a transmissão humana deste vírus (Smith et al., 1933; Byerly, 2005; Barberis et al., 2016). Reid e seus colaboradores (1999) publicaram a sequência completa do gene da hemaglutinina do vírus da pandemia da Gripe Espanhola de 1918, enquanto a sequência do gene da neuraminidase foi publicada no ano seguinte. O RNA do vírus da gripe foi isolado, entre outros, de tecidos pulmonares fixados em formalina e embebidos em parafina obtidos durante a autópsia de dois soldados, que morreram de gripe em 1918. Através da abordagem molecular reversa do vírus, conseguiu-se obter as sequências de RNA viral e a reconstrução completa do vírus pandémico de 1918. A análise molecular demonstrou que o vírus pertencia ao subtipo influenza A (H1N1) (Tumpey et al., 2005).

\section{A Pandemia no Contexto da I Guerra Mundial}

A pandemia de 1918 foi causada por um vírus Influenza H1N1 extremamente virulento, e ficou conhecida como Gripe Espanhola ou Pneumónica (Nelson et al., 2008). Provocava grande mortalidade. As mortes ocorriam rapidamente após os primeiros sintomas, e a maioria das vítimas era jovens adultos. Em 1918, devido à pressão para manter a moral elevada durante a I Guerra Mundial, as autoridades governamentais não revelaram a gravidade da doença aos seus povos e várias autoridades de saúde a nível local recusaram-se a comunicar o número de pessoas afetadas e, o número de mortes. Consequentemente, foi muito difícil avaliar o impacto da doença na época (Martini et al., 2019). A pandemia matou mais de 50 milhões de pessoas e causou mais de 500 milhões de infeções. Nos teatros de guerra e nas trincheiras, na I Guerra Mundial, a pandemia atingiu milhões de soldados em todo o mundo, causando a morte de 100 mil jovens militares, contudo, não está claro se teve impacto no término da guerra (Shanks, 2015).

A doença disseminou-se por Portugal, Espanha, França, Grã-Bretanha e Itália. Na Europa, a mortalidade foi mais elevada em Itália. Em termos mundiais, foi em países como a Índia, Madagáscar, México, África, Nova Zelândia, Guatemala e China (Martini et al., 2019). 
Como a Espanha foi um país neutro na I Guerra Mundial, os jornais não eram censurados e podiam fazer reportagens sobre os efeitos devastadores que o vírus provocava naquele país. De forma errada percebeu-se que a pandemia originou-se na Espanha e levou à denominação incorreta da doença como "Gripe Espanhola". Durante o outono de 1918, as primeiras páginas dos jornais espanhóis foram preenchidas com os nomes daqueles que morreram de pandemia no país. Em outros países europeus, porém, a imprensa absteve-se de relatar notícias da disseminação da infeção, de modo a não alarmar a população em geral, que já sofria as privações causadas pela I Guerra Mundial. Em países que silenciaram a imprensa, a confiança na autoridade deteriorou-se com o aumento do número de mortos, o que aumentou a vulnerabilidade da população (Radusin, 2012a, Radusin, 2012b).

Embora seja difícil atribuir uma data específica ao início da pandemia, é clara a sua associação aos milhões de homens que ocuparam os campos militares e as trincheiras durante a I Guerra Mundial. Foi sugerido que o início da pandemia ocorreu numa base militar britânica em Étaples, na costa do Norte da França em que os soldados se amontoavam, havia pântanos por perto povoado por inúmeras aves migratórias, quintas com porcos, patos e gansos que serviam para alimentar os soldados. Estas condições podem ter contribuído para um surto de infeção respiratória aguda entre dezembro de 1916 e março de 1917, que se assemelhava clinicamente à pandemia de gripe de 1918. A origem da pandemia também foi associada aos soldados indochineses do antigo reino de Annam que combatiam na França entre 1916 e 1918. Entre estes soldados, foram observadas várias epidemias de infeções respiratórias agudas, conhecidas como "Pneumonia de Annamite". No entanto, o primeiro surto considerado como causado pela pandemia de gripe de 1918 ocorreu em Camp Funston, um campo de treino do Exército dos EUA em Kansas (Erkoreka, 2009; Wever \& van Bergen, 2014). Há registos que a 4 de março de 1918, Albert Gitchel, um cozinheiro de Camp Fuston, no Kansas apresentou um quadro gripal constituído por tosse, febre e dores de cabeça. Foi um dos primeiros casos identificados na história da Gripe Espanhola. Em 3 semanas, 1100 soldados foram hospitalizados e outros milhares foram afetados (Wever \& van Bergen, 2014).

A Gripe Espanhola cursou com 3 ondas pandémicas. A primeira onda não foi considerada universalmente como gripe. Os sintomas eram semelhantes aos da gripe pandémica, mas a doença era muito leve e de curta duração e as taxas de mortalidade eram semelhantes às observadas em outros surtos sazonais de vírus influenza (Radusin, 2012a). A segunda onda da pandemia disseminou-se globalmente no outono, entre setembro e novembro de 1918, após um período de calmaria no verão. $\mathrm{O}$ vírus ressurgiu de forma extremamente virulenta. Provavelmente esta onda foi causada por uma mutação da estirpe do vírus inicial. Foi responsável pela maioria das dezenas de milhões de mortes (Taubenberger \& Morens, 2006; Wever \& van 
Bergen, 2014). A maioria dos casos de doença e morte devido à pandemia ocorreu na segunda onda (Radusin, 2012b). Em dezembro de 1918, grande parte do mundo estava uma vez mais livre da gripe e, no início de 1919, a Austrália até suspendeu as suas medidas de quarentena. Na última semana de janeiro de 1919, a terceira onda chegou a Nova Iorque, e Paris foi atingida durante os processos de negociação de paz do pós-guerra. Em global, menos pessoas foram afetadas pela doença durante a onda final do vírus influenza, no entanto, é possível que as taxas de mortalidade tenham sido tão elevadas quanto durante a segunda onda (Taubenberger \& Morens, 2006).

\section{A Pandemia em Portugal}

O primeiro surto chegou a Portugal na primavera de 1918, mantendo-se até julho (Sobral, 2018). Em 31 de maio de 1918, foi emitido o primeiro alerta a todas as delegações de saúde portuguesas, para iniciar os preparativos para o surgimento de uma epidemia que representava uma ameaça imediata para os municípios que faziam fronteira com Espanha (Jorge, 1918). O primeiro lugar a ser afetado pela pandemia foi Vila Viçosa na fronteira do distrito de Évora. Segundo os registos, a doença foi trazida pelos trabalhadores agrícolas que vieram de Badajoz e Olivença (Espanha). Em 6 de junho de 1918, a pandemia alastrou a Terrugem e Assumar (perto de Arronches) na região de Portalegre que também faz fronteira com a Estremadura Espanhola. No dia 10 de junho de 1918 a epidemia atingiu a cidade do Porto e em 11 de junho foi anunciado que foram registados 50 casos na prisão de Monsanto em Lisboa. Espanha encerrou as fronteiras com França no dia 20 de setembro de 1918 (e com Portugal no dia 30 de setembro de 1918. Em Espanha durante a primavera, a epidemia era denominada "O Mal da moda" ou o "Soldado de Nápoles" que era a música da moda na época (Erkoreka, 2010). Em Portugal era conhecida como "Pneumónica", "Espanhola" ou "Bailarina" (Esteves e Pinto, 2020). Conforme as estatísticas oficiais, morreram em Portugal cerca de 60 mil pessoas, perto de 56 mil pessoas em 1918 e 3 mil em 1919 (Sobral, 2019). Na fatídica pandemia morreram personalidades portuguesas famosas como o pintor modernista Amadeo SouzaCardoso, o pintor Guilherme Santa-Rita, os dois pastorinhos de Fátima, Jacinta e Francisco Marto, o maestro David de Sousa e o músico António Fragoso.

\section{Aspetos Epidemiológicos da Gripe Espanhola}

A Pneumónica como a infeção ficou conhecida em Portugal, atingiu diferentes grupos de idades, exibindo a chamada "tendência em W", considerada uma assinatura desta gripe pandémica. As infeções atingiam tipicamente o pico em crianças e idosos, com um pico intermédio em jovens, o segmento mais saudável da população, com idades compreendidas entre 20 e 40 anos, e uma média de idades de 28 anos (Paynter et al., 2011; Gagnon et al., 2013; Wilson et al., 2014). Muitos milhares de soldados 
da I Guerra Mundial morreram de gripe, ao contrário dos generais e almirantes que tinham idades superiores (Shanks et al., 2010). Também os soldados provenientes das áreas rurais que tiveram poucas infeções respiratórias anteriores e, pouca exposição a agentes infeciosos, apresentaram taxas de mortalidade mais elevadas em comparação com os seus congéneres urbanos (Paynter et al., 2011).

A razão para jovens adultos saudáveis serem infetados, ainda não está completamente explicada, mas provavelmente está associada ao estado imunológico devido à falta de imunidade pré-existente nesta população, isto é devida à falta de anticorpos específicos para vírus e/ou de reações cruzadas pré-/existentes (Short et $a l, 2018)$. Também foi sugerido que a geração de uma resposta inflamatória excessiva ("tempestade de citocinas") em adultos infetados com o vírus de 1918 pode ter contribuído para o excesso de mortalidade visto que nesta faixa etária também acabava por destruir os pulmões (Taubenberger \& Morens, 2006; Erkoreka, 2010; Barberis et al., 2016). Mais de $99 \%$ das infeções fatais ocorreram em pessoas com $<65$ anos e quase $50 \%$ de todas as mortes relacionadas à Gripe Espanhola ocorreram em pessoas com idade entre 20 e 40 anos. As taxas de mortalidade por gripe e pneumonia nos infetados com idade entre 15-34 anos foram mais de 20 vezes superiores do que nos anos anteriores e, o risco absoluto de morte relacionada à gripe espanhola foi maior naqueles com $<65$ anos do que naqueles com $>65$ anos (Taubenberger \& Morens, 2006).

Um facto curioso é que os grupos ocupacionais expostos como médicos e enfermeiros tiveram taxas de mortalidade relacionadas à pandemia baixas e, semelhantes às taxas de outros grupos ocupacionais. Isto demonstra que a relação dinâmica entre o hospedeiro e o vírus, os aspetos epidemiológicos e as propriedades específicas do hospedeiro que contribuíram para a infeção ainda permanecem desconhecidas (Morens \& Fauci, 2007; Shanks et al., 2011).

Os fatores que predispuseram ao agravamento da pandemia foram vários. Acreditava-se que uma das causas era a má qualidade dos alimentos racionados na época da crise epidémica. A gravidade da pandemia foi acentuada pela desnutrição devido à guerra, embora esta associação não tenha sido confirmada. Isto porque a doença teve igual gravidade em países neutros ou não completamente envolvidos na guerra, como a Espanha e, afetou igualmente as classes privilegiadas, como o Rei de Espanha Afonso XIII. As teorias da conspiração teorizavam ser um agente de bioterrorismo, desencadeado por uma guerra bacteriológica travada pelos alemães contra o inimigo (Martini et al., 2019)

É inegável que a guerra desempenhou um papel importante durante a pandemia de influenza. Fatores como concentração de homens, circulação de tropas, mobilização / desmobilização de soldados, quartéis lotados, reuniões relacionadas à 
propaganda de guerra criaram um ambiente favorável para uma pandemia, assim como, os pratos sujos, as moscas, a poeira, ou mesmo as condições adversas do clima. Algumas más decisões foram tomadas, como evitar a quarentena e proibições de viagens para avanços militares (Matta et al., 2020). Em campos sobrelotados, o risco de gripe aumentou 10 vezes (Nickol et al., 2019). A pandemia agravou o saneamento precário, a fome, a superlotação ou outras doenças infeciosas comuns à época, como o tifo, ou a tuberculose (Matta et al., 2020).

Por outro lado, o retorno dos soldados que estavam na frente da guerra, a migração dos refugiados e a mobilidade em atividades extra domésticas favoreceram a rápida propagação do vírus desde o início da primeira onda pandémica. As medidas preventivas de saúde pública foram essenciais de modo a conter a disseminação da doença (Reid et al., 2004).

A Gripe Espanhola chegou a Portugal quando o país passava por uma grave crise económica. A fome e a miséria facilitaram a disseminação da doença. A escassez de bens era generalizada, principalmente o leite, que era conhecido como alimento recomendado para o tratamento da gripe (Esteves \& Pinto, 2020). Há um século, Portugal tinha condições higiénicas e sanitárias muito deficientes, falta de médicos e de medicamentos, para além do resto dos fatores que afetaram a pandemia a nível global (Sobral et al., 2009).

\section{Quadro Clínico e Lesional - Quando o Paciente Azulava}

Os sintomas registados incluíam hemorragia nasal, pneumonia, encefalite, temperatura superior a $40^{\circ} \mathrm{C}$, nefrite acompanhada de urina com sangue e coma (Tsoucalas et al., 2015). Em termos clínicos, um dos sintomas frequentemente referido era a cianose da pele que ficava incrivelmente azulada, rotulada na época de "cianose heliotrópica" (Shanks, 2014) (Tabela 1).

$\mathrm{O}$ vírus infetava as células do epitélio respiratório causando uma traqueobronquite aguda que se podia estender para o parênquima pulmonar e causar pneumonite viral (Taubenberger e Morens, 2008; Morens et al., 2008). A destruição do epitélio respiratório permitia a entrada de bactérias que colonizavam outras partes da árvore respiratória para dar início a pneumonia bacteriana (Brundage, 2006, Rosner, 2010; Fornasin et al., 2018; Ferrari, 2020). A maioria das mortes ocorria 7 dias após o início da doença e foram o resultado de pneumonia bacteriana secundária causada por agentes bacterianos comuns no trato respiratório, como Haemophilus influenzae, Streptococcus pneumoniae, S. pyogenes ou Staphylococcus aureus (Shanks \& Brundage, 2012; Opie et al., 1921). Estava-se na era pré-antibiótica e a penicilina ainda não era usada como antibiótico. Estima-se que a pneumonia bacteriana secundária matou cerca de um em cada três pacientes (Vaughan \& Palmer, 1919). 
Tabela 1 - Principais sintomas e lesões da Gripe Espanhola pandémica de 1918 (Adaptado de: Taubenberger \& Morens, 2008; Morens et al., 2008; Shanks, 2014; Tsoucalas et al., 2015).

\begin{tabular}{l}
\hline Sintomas e Lesões \\
\hline Temperatura superior a $40^{\circ} \mathrm{C}$ \\
\hline Cianose (cianose heliotrópica) \\
\hline Hemorragia nasal \\
\hline Encefalite \\
\hline Traqueobronquite aguda \\
\hline Pneumonia \\
\hline
\end{tabular}

O nítido contraste nas expressões clínicas das infeções durante a primeira e a segunda onda sugeriu que as mesmas foram causadas por diferentes estirpes do vírus da gripe. Se as duas primeiras ondas epidémicas da pandemia de 1918-19 foram causadas pelo mesmo vírus influenza A (H1N1) através da reação cruzada, as pessoas afetadas durante a primeira onda deveriam ter sido protegidas contra infeção e, por sua vez, doença, não devendo sofrer de pneumonia secundária, e morte durante a segunda onda. A proteção contra a infeção teria derivado de anticorpos neutralizantes contra os mesmos antigénios de superfície viral ou semelhantes (por exemplo, hemaglutinina) (Shanks \& Brundage, 2012).

\section{O Pandemónio da Gripe Espanhola}

A Gripe Espanhola foi um verdadeiro pandemónio. Embora tenha trazido conhecimento e muitas lições que o mundo usou 100 anos depois. Em primeiro, as medidas de contenção da gripe afetaram fortemente o dia a dia dos cidadãos. Enquanto alguns aceitaram as mudanças que lhes foram impostas, outros protestaram contra as regulamentações que consideraram injustas. Alguns pediram métodos mais rígidos, enquanto outros quebraram descaradamente as novas regras que deveriam protegê-los (Ott et al., 2007).

As medidas draconianas impostas a nível mundial e extremamente rígidas para a época aplicadas em alguns países incluíram o encerramento de locais como teatros, escolas, enquanto as reuniões em massa, como casamentos e funerais, foram proibidos para evitar a sobrelotação (Frost, 1919; Johnson, 2006; Bootsma \& Ferguson, 2007; Hatchett et al., 2007). Nas igrejas foram proibidos os sermões longos e as instruções eram que os serviços religiosos como as missas aos domingos não durassem mais do que 5 minutos. Foram proibidas multidões fora das lojas e limitado o número de passageiros em transportes públicos. Estas medidas por si só, não foram consideradas suficientes (Matta et al., 2020). Contudo, a taxa de 
mortalidade foi menor em cidades que implementaram rapidamente estas intervenções não farmacêuticas alguns dias após os primeiros casos terem sido registados, em comparação com aquelas que esperaram algumas semanas para responder (Bootsma \& Ferguson, 2007; Hatchett et al., 2007).

Tal como a nível mundial, em Portugal encerraram-se os locais de espetáculos, feiras, romarias, cafés e clubes e proibiram-se as procissões. A morte e como se morria foi também afetado: houve proibição dos funerais públicos, o sepultamento ocorria 24 horas após a morte, fazia-se a desinfeção das casas dos falecidos. Contudo, com o crescente aumento da mortandade, os coveiros começaram a recusar-se a sepultar os mortos, já não havia lugares nos cemitérios e, os mortos foram sepultados em valas comuns. Até os sinos foram proibidos de dobrar a finados (Esteves \& Pinto, 2020).

Em 1918, as máscaras, feitas de gaze, eram chamadas "focinhos", "escudos de germes" e "armadilhas de lixo". Algumas pessoas abriram buracos nas suas máscaras para fumar charutos. Outros colocaram-nas nos seus cães para gozar com a situação. Os bandidos usavam-nas para assaltar bancos. Tal como agora, na pandemia de Covid19, os profissionais de saúde e as autoridades sanitárias pediram o seu uso para retardar a disseminação da doença. Tal como agora, algumas pessoas resistiram. Nos Estados Unidos, foram administradas duas vacinas e nenhuma delas foi eficaz, pois nenhuma continha o vírus da gripe (Matta et al., 2020).

Embora as pessoas não tivessem a certeza do agente etiológico, o consenso era que se tratava de uma doença transmitida pelo ar e o uso de uma máscara facial preveniria infeções (Crosby, 1976). Consequentemente, muitas cidades e regiões, incluindo a Cidade da Guatemala, São Francisco nos EUA e certas localidades do Japão, tornaram obrigatório o uso de máscara facial em locais públicos, e desenvolveram campanhas educacionais para fazer cumprir este regulamento (Crosby, 1976; Rice \& Palmer, 1993; Rice, 2011).

A falta de intervenções médicas eficazes em 1918 significou que era muitas vezes melhor ser tratado em casa pela própria família do que ser admitido nas enfermarias dos hospitais que estavam caóticos e sobrelotados, para além de aumentarem a exposição a muitos agentes patogénicos respiratórios além do vírus da gripe (Oswald et al., 1958; Brundage \& Shanks, 2008).

As medidas implementadas para conter a pandemia de 1918 afetaram a vida cotidiana dos cidadãos. Nos EUA em Minneapolis, o encerramento dos locais públicos foi anunciado com alguma antecedência. Como consequência as pessoas correram para realizar as atividades que a seguir seriam proibidas, resultando nas mesmas condições de sobrelotação que a proibição queria evitar. Também nos EUA, todos os casos de gripe em 1918 deveriam ser notificados a um médico, que tinha de isolar o caso na sua casa e notificar o departamento de saúde. Vários problemas surgiram. Os médicos, 
assim como, os pacientes, hesitaram em chamar a atenção para os casos. Os médicos não relatavam os casos para evitar que as casas fossem colocadas em quarentena. Os casos sintomáticos queriam escapar do isolamento não procurando atendimento médico quando ficaram muito doentes (Matta et al., 2020).

Quando a gravidade da segunda onda de gripe tornou-se aparente, muitos países impuseram medidas de quarentena rígidas a todos os navios que chegavam para tentar prevenir a propagação da gripe. Na maioria das vezes, essas tentativas foram mal sucedidas (Johnson, 2006). As medidas de quarentena foram implementadas tarde demais e, o vírus já estava presente no país ou a quarentena foi violada por indivíduos infetados que ainda não eram sintomáticos (Crosby, 1976; Tomkins, 1992).

Mas foram vários os aspetos melhorados em termos sanitários. Durante esta pandemia foram organizados serviços para a remoção de resíduos humanos, efetuada a regulamentação do uso de casas de banho públicas, a inspeção do leite e outros produtos de origem alimentar. Foi proibido cuspir na rua, o que determinou o aparecimento de escarradeiras de bolso e, o aparecimento de anúncios nos jornais e panfletos que anunciavam as virtudes terapêuticas das águas e a lavagem das mãos (Martini et al., 2019). A promoção da higiene adequada efetuada por campanhas (por exemplo, lavagem frequente das mãos) também deve ter ajudado a limitar a propagação do vírus durante a pandemia de 1918, dado que os vírus da gripe são transmissíveis por contacto direto com as mãos (Thomas et al., 2014). Assim, a cultura tradicional japonesa em relação às doenças e enfermidades pode ter contribuído para uma mais baixa mortalidade pandémica a nível nacional, já que as crianças japonesas desde muito pequenas são ensinadas a tirar os sapatos e lavar as mãos ao voltarem para casa (Rice \& Palmer, 1993). Também o isolamento de pacientes com gripe para minimizar a sua exposição a outras pessoas, mostrou diminuir as taxas de mortalidade (Vaughan \& Palmer, 1919). As cidades que impuseram múltiplas medidas de contenção social poucos dias após a deteção dos primeiros casos locais tiveram taxas de mortalidade até $50 \%$ mais baixas do que outras cidades que esperaram semanas para responder. A implementação precoce de algumas intervenções, incluindo o encerramento de escolas, igrejas e teatros, foi associada a taxas de mortalidade mais baixas, mas nenhuma intervenção isolada mostrou uma associação com melhores resultados (Hatchett et al., 2007). Além disso, o benefício dessas múltiplas intervenções era extremamente limitado se implementado tardiamente ou levantado muito cedo, o que indica que o momento adequado da resposta é crucial para conter os efeitos de uma pandemia. São Francisco, St. Louis, Milwaukee e Kansas City nos EUA que tiveram as intervenções de saúde pública mais eficazes, conseguiram reduzir as taxas de transmissão entre 30 e 50\% (Bootsma \& Ferguson, 2007). 


\section{O Futuro e a Mitigação das Pandemias, as Lições Aprendidas Passados} 100 Anos

As pandemias de gripe ocorrem, desde o século XVI, regularmente a cada 30 a 40 anos. Os especialistas em gripe consideram a possibilidade de outra pandemia de vírus influenza, não em termos de "se", mas de "quando" (Ott et al., 2007).

Devido à globalização e interconexão dos tempos modernos, as pandemias permanecem como ameaças perenes para as sociedades humanas. É certo que nunca estaremos totalmente preparados para futuras pandemias. Contudo, sabemos, que as pandemias impactam desproporcionalmente as classes socialmente desfavorecidas. Um desafio futuro é a mitigação das desigualdades de saúde e vulnerabilidades sociais estruturais que muitas pessoas enfrentam globalmente (Mujica et al., 2020).

Em 1918-1919, apenas as medidas não farmacêuticas de saúde pública eram as armas eficazes contra a doença, pois não estavam disponíveis vacinas ou antivirais. A pandemia de Gripe Espanhola levou a enormes melhorias na saúde pública a nível global. Levou a várias estratégias de educação em saúde, medidas de isolamento, saneamento e vigilância adotadas, o que levou à melhoria do conhecimento sobre a transmissão e, ainda hoje implementadas. Levou a enormes melhorias na saúde pública. Melhorou o conhecimento sobre a gripe e levou à aquisição de conhecimentos que ainda hoje são usados para conter a transmissão de várias doenças infeciosas (Martini et al., 2019)

Embora já tenha se passado um século desde o início da pandemia de Gripe Espanhola, as lições dessa catástrofe global de saúde continuam a informar a preparação para a pandemia dos dias modernos. As investigações da pandemia, incluindo aquelas com o vírus reconstruído, permitiram aos cientistas, bem como ao público global, compreender os mecanismos por trás do surgimento da pandemia e da escalada para a crise de saúde pública. Também permite aos cientistas prever os riscos potenciais para a saúde pública que podem ser causados por novos vírus pandémicos. Por exemplo, a sequenciação do vírus pandémico de 1918 revelou semelhanças na proteína H1 do vírus pandémico de 2009, permitindo aos investigadores prever que uma falta de proteção, portanto, uma elevada taxa de mortalidade podia ser observada em adultos jovens saudáveis durante a pandemia H1N1 de 2009 (Smith et al., 2009; Gras et al., 2010; Pearce et al., 2012).

Aprendendo com as lições da Gripe Espanhola, o tempo para o desenvolvimento, produção em massa e aprovação pelas entidades competentes da vacina na pandemia de 1918-1919, mostrou o quanto é importante alocar a maior parte dos nossos esforços de saúde pública para intervenções sanitárias e de epidemiovigilância como as medidas de prevenção e para o cuidado médico de 
casos sintomáticos para reduzir as fatalidades até que vacinas seguras e eficazes sejam totalmente desenvolvidas e distribuídas (Mujica et al., 2020).

Nos últimos anos, o medo da recorrência de uma pandemia de gripe semelhante à de 1918 motivou o planeamento, a preparação e alocação de recursos pelas entidades governamentais e organizações não governamentais em todo o mundo (Morens et al., 2010).

\section{Conclusões}

Embora nada nos preparasse para a pandemia da Covid-19, analisar a pandemia de Gripe Espanhola de 1918 é uma oportunidade para considerar a crise atual de Covid-19 de uma perspetiva diferente e otimista. Das lições melhor aprendidas da pandemia de há 100 anos é que a educação para a saúde e a literacia em saúde é fundamental no controlo e prevenção de pandemias (Spring, 2020). Quando uma doença infeciosa se propaga pela população, quer esteja mais restrita geográfica ou globalmente, são os conhecimentos, atitudes, práticas e resiliência da população que travam o avanço da pandemia e determinam a escala de gravidade que esta atinge, já que dependem da natureza e complexidade do comportamento humano, refletindo diretamente quem somos, o que fazemos e como vivemos e interagimos com outras pessoas, animais e meio ambiente (Fauci \& Morens, 2012). Para isso é necessário que exista um bom conhecimento sobre o agente que a provoca, a sua transmissão, e, principalmente, as medidas preventivas para proteção

própria e dos outros. É, por isso, indispensável apostar na instrução da população para se obter o resultado mais favorável possível num contexto de pandemia através de medidas de educação e promoção da saúde.

\section{Referências}

Barberis, I., Myles, P., Ault, S. K., Bragazzi, N. L., \& Martini, M. (2016). History and evolution of influenza control through vaccination: from the first monovalent vaccine to universal vaccines. Journal of Preventive Medicine and Hygiene, 57(3), E115-E120.

Bazin, H. (2011). Vaccination: From Lady Montagu to Jenner Pasteur and Genetic Engineering. John Libbey Eurotext Ltd; UK ed.

Bootsma, M. C., \& Ferguson, N. M. (2007). The effect of public health measures on the 1918 influenza pandemic in U.S. cities. Proceedings of the National Academy of Sciences of the United States of America, 104(18), 7588-7593. https://doi.org/10.1073/pnas.0611071104 
Brundage, J. F., \& Shanks, G. D. (2008). Deaths from bacterial pneumonia during 1918-19 influenza pandemic. Emerging Infectious Diseases, 14(8), 11931199. https://doi.org/10.3201/eid1408.071313

Brundage, J. F. (2006). Interactions between influenza and bacterial respiratory pathogens: implications for pandemic preparedness. The Lancet. Infectious Diseases, 6(5), 303-312. https://doi.org/10.1016/S1473-3099(06)70466-2

Byerly CR. Fever of War. The Influenza Epidemic in the U.S. Army during World War I. New York, NY: New York University Press; 2005.

Coltart, C. E. M., Lindsey, B., Ghinai, I., Johnson, A. M., \& Heymann, D. L. (2017). The Ebola outbreak, 2013-2016: Old lessons for new epidemics. Philosophical Transactions of the Royal Society B: Biological Sciences, 372(1721), 2013-2016. https://doi.org/10.1098/rstb.2016.0297

Crosby A. W. (1976). Epidemic and Peace 1918. Santa Barbara, CA: Abc-Clio.

Erkoreka, A. (2009). Origins of the Spanish Influenza pandemic (1918-1920) and its relation to the First World War. Journal of Molecular and Genetic Medicine: An International Journal of Biomedical Research, 3(2), 190-194. https://www.ncbi.nlm.nih.gov/pmc/articles/PMC2805838/

Erkoreka, A. (2010). The Spanish influenza pandemic in occidental Europe (19181920) and victim age. Influenza and Other Respiratory Viruses, 4(2), 81-89. https://doi.org/10.1111/j.1750-2659.2009.00125.x

Esteves, A. P., \& Pinto, S. (2020). A gripe espanhola em Portugal: a construção da memória. O trabalho médico e a assistência hospitalar. Mundos do Trabalho, 12, 1-15. https://doi.org/10.5007/1984.9222.2020.e75134

Fauci, A. S., \& Morens, D. M. (2012). The Perpetual Challenge of Infectious Diseases. New England Journal of Medicine, 366(5), 454-461. https://doi.org/10.1056/nejmra1108296

Ferrari, L. (2020). Spanish flu in Turin as told by historical autopsy reports. Pathologica, 112(2), 110-114. https://doi.org/10.32074/1591-951X-2-20

Fineberg, H. V. (2014). Pandemic Preparedness and Response - Lessons from the H1N1 Influenza of 2009. New England Journal of Medicine, 370(14), 13351342. https://doi.org/10.1056/nejmra1208802

Fornasin, A., Breschi, M., \& Manfredini, M. (2018). Spanish flu in Italy: new data, new questions. Le Infezioni in Medicina 26(1), 97-106.

Frost, W. H. (1919). Public health weekly reports for August 15, 1919. Public Health Reports, 34, 1823-1926. https://doi.org/10.2307/4575271

Gagnon, A., Miller, M. S., Hallman, S. A., Bourbeau, R., Herring, D. A., Earn, D. J., \& Madrenas, J. (2013). Age-specific mortality during the 1918 influenza pandemic: unravelling the mystery of high young adult mortality. PloS one, 8(8), e69586. https://doi.org/10.1371/journal.pone.0069586 
Gras, S., Kedzierski, L., Valkenburg, S. A., Laurie, K., Liu, Y. C., Denholm, J. T., Richards, M. J., Rimmelzwaan, G. F., Kelso, A., Doherty, P. C., Turner, S. J., Rossjohn, J., \& Kedzierska, K. (2010). Cross-reactive CD8+ T-cell immunity between the pandemic H1N1-2009 and H1N1-1918 influenza A viruses. Proceedings of the National Academy of Sciences of the United States of America, 107(28), 12599-12604. https://doi.org/10.1073/pnas.1007270107

Hatchett, R. J., Mecher, C. E., \& Lipsitch, M. (2007). Public health interventions and epidemic intensity during the 1918 influenza pandemic. Proceedings of the National Academy of Sciences of the United States of America, 104(18), 7582-7587. https://doi.org/10.1073/pnas.0610941104

Johnson, N. (2006). Britain and the 1918-19 Influenza Pandemic: A Dark Epilogue. Abingdon: Taylor \& Francis Ltd.

Jones, K. E., Patel, N. G., Levy, M. A., Storeygard, A., Balk, D., Gittleman, J. L., \& Daszak, P. (2008). Global trends in emerging infectious diseases. Nature, 451(7181), 990-993. https://doi.org/10.1038/nature06536

Jorge, R. (1918). A influenza. Nova incursão peninsular. Relatório apresentado ao Conselho Superior de Higiene na sessão de 18 de junho de 1918. Lisboa: Imprensa Nacional, 1918.

Krammer, F., Smith, G., Fouchier, R., Peiris, M., Kedzierska, K., Doherty, P. C., Palese, P., Shaw, M. L., Treanor, J., Webster, R. G., \& García-Sastre, A. (2018). Influenza. Nature reviews. Disease primers, 4(1), 3. https://doi.org/10.1038/s41572-018-0002-y

Martini, M., Gazzaniga, V., Bragazzi, N. L., \& Barberis, I. (2019). The Spanish Influenza Pandemic: a lesson from history 100 years after 1918. Journal of Preventive Medicine and Hygiene, 60(1), E64-E67. https://doi.org/gktfw8

Matta, S., Arora, V. K., \& Chopra, K. K. (2020). Lessons to be learnt from 100 year old 1918 influenza pandemic viz a viz 2019 corona pandemic with an eye on NTEP. The Indian Journal of Tuberculosis, 67(4S), S132-S138. https://doi.org/10.1016/j.ijtb.2020.09.032

McArthur, D. B. (2019). Emerging Infectious Diseases. The Nursing Clinics of North America, 54(2), 297-311. https://doi.org/10.1016/j.cnur.2019.02.006

Morens, D.M., \& Fauci, A. S. (2007). The 1918 influenza pandemic: insights for the 21st century. The Journal of Infectious Diseases, 195(7), 1018-1028. https://doi.org/10.1086/511989

Morens, D. M., \& Fauci, A. S. (2013). Emerging Infectious Diseases: Threats to Human Health and Global Stability. PLoS Pathogens, 9(7), 7-10. https://doi.org/10.1371/journal.ppat.1003467

Morens, D. M., Taubenberger, J. K., \& Fauci, A. S. (2008). Predominant role of bacterial pneumonia as a cause of death in pandemic influenza: implications for pandemic influenza preparedness. The Journal of Infectious Diseases, 198(7), 962-970. https://doi.org/10.1086/591708 
Morens, D. M., Taubenberger, J. K., Harvey, H. A., \& Memoli, M. J. (2010). The 1918 influenza pandemic: lessons for 2009 and the future. Critical Care Medicine, $38(4$ Suppl), e10-e20. https://doi.org/10.1097/CCM.0b013e3181ceb25b

Mujica, G., Sternberg, Z., Solis, J., Wand, T., Carrasco, P., Henao-Martínez, A. F., \& Franco-Paredes, C. (2020). Defusing COVID-19: Lessons Learned from a Century of Pandemics. Tropical Medicine and Infectious Disease, 5(4), 182. https://doi.org/10.3390/tropicalmed5040182

Murray, M. J. (2015). Ebola Virus Disease: A Review of Its Past and Present. Anesthesia and Analgesia, 121(3), 798-809. https://doi.org/f7p5t6

Nelson, M. I., Viboud, C., Simonsen, L., Bennett, R. T., Griesemer, S. B., St George, K., Taylor, J., Spiro, D. J., Sengamalay, N. A., Ghedin, E., Taubenberger, J. K., \& Holmes, E. C. (2008). Multiple reassortment events in the evolutionary history of H1N1 influenza A virus since 1918. PLoS Pathogens, 4(2), e1000012. https://doi.org/10.1371/journal.ppat.1000012

Nickol, M.E., \& Kindrachuk, J. (2019). A year of terror and a century of reflection: perspectives on the great influenza pandemic of 1918-1919. BMC Infectious Diseases, 19, 117. https://doi.org/10.1186/s12879-019-3750-8

Opie, E. L., Blake, F. G., Small, J. C., \& Rivers, T. M. (1921). Epidemic respiratory disease: the pneumonias and other infections of the respiratory tract accompanying influenza and measles. St. Louis: CV Mosby; 1921

Oswald, N. C., Shooter, R., Curwen, M. (1958). Pneumonia complicating Asian influenza. $B M J, 2,1305$.

Ott, M., Shaw, S. F., Danila, R. N., \& Lynfield, R. (2007). Lessons learned from the 1918-1919 influenza pandemic in Minneapolis and St. Paul, Minnesota. Public Health Reports (Washington, D.C.: 1974), 122(6), 803-810. https://doi.org/10.1177/003335490712200612

Paynter, S., Ware, R. S., Shanks, G. D. (2011). Host and environmental factors reducing mortality during the 1918-1919 influenza pandemic. Epidemiology and Infection, 139,1425e 30 .

Pearce, M. B., Belser, J. A., Gustin, K. M., Pappas, C., Houser, K. V., Sun, X., Maines, T. R., Pantin-Jackwood, M. J., Katz, J. M., \& Tumpey, T. M. (2012). Seasonal trivalent inactivated influenza vaccine protects against 1918 Spanish influenza virus infection in ferrets. Journal of Virology, 86(13), 7118-7125. https://doi.org/10.1128/JVI.00674-12

Radusin, M. (2012a). The Spanish flu-Part I: the first wave. Vojnosanitetski Pregled, 69(9), 812-817.

Radusin M. (2012b). The Spanish flu--part II: the second and third wave. Vojnosanitetski Pregled, 69(10), 917-927.

Raoult, D., Mouffok, N., Bitam, I., Piarroux, R., \& Drancourt, M. (2013). Plague: History and contemporary analysis. Journal of Infection, 66(1), 18-26. https://doi.org/10.1016/j.jinf.2012.09.010 
Reid, A. H., Fanning, T. G., Hultin, J. V., \& Taubenberger, J. K. (1999). Origin and evolution of the 1918 "Spanish" influenza virus hemagglutinin gene. Proceedings of the National Academy of Sciences of the United States of America, 96(4), 1651-1656. https://doi.org/10.1073/pnas.96.4.1651

Reid, A. H., Taubenberger, J. K., \& Fanning, T. G. (2004). Evidence of an absence: the genetic origins of the 1918 pandemic influenza virus. Nature reviews. Microbiology, 2(11), 909-914. https://doi.org/10.1038/nrmicro1027

Rewar, S., Mirdha, D., \& Rewar, P. (2015). Treatment and Prevention of Pandemic H1N1 Influenza. Annals of Global Health, 81(5), 645-653. https://doi.org/10.1016/j.aogh.2015.08.014

Rice, G. W. (2011). "Japan and New Zealand in the 1918 influenza pandemic: comparative perspectives on official responses and crisis management," in Spanish Influenza Pandemic of 1918-1919: New Perspectives, ed. D. Killingray (Melbourne, VIC: Routledge).

Rice, G. W., \& Palmer, E. (1993). Pandemic influenza in Japan, 1918-19, mortality patterns and official responses. Journal of Japanese Studies, 19, 389-420. https://doi.org/10.2307/132645

Rosner, D. (2010). "Spanish flu, or whatever it is...": The paradox of public health in a time of crisis. Public Health Reports (Washington, D.C.: 1974), 125 (Suppl 3), 38-47.

Shanks, G. D., Mackenzie, A., McLaughlin, R., Waller, M., Dennis, P., Lee, S. E., \& Brundage, J. F. (2010). Mortality risk factors during the 1918-19 influenza pandemic in the Australian army. The Journal of Infectious Diseases, 201(12),1880e9. https://doi.org/10.1086/652868

Shanks, G. D. (2014). How World War 1 changed global attitudes to war and infectious diseases. Lancet, 384,1699e707.

Shanks, G. D. (2015). Insights from unusual aspects of the 1918 influenza pandemic. Travel Medicine and Infectious Disease, 13(3), 217-222. https://doi.org/10.1016/j.tmaid.2015.05.001

Shanks, G. D., \& Brundage, J. F. (2012). Pathogenic responses among young adults during the 1918 influenza pandemic. Emerging Infectious Diseases, 18(2), 201-207. https://doi.org/10.3201/eid1802.102042

Shanks, G. D., MacKenzie, A., Waller, M., \& Brundage, J. F. (2011). Low but highly variable mortality among nurses and physicians during the influenza pandemic of 1918-1919. Influenza and Other Respiratory Viruses, 5(3), 213219. https://doi.org/10.1111/j.1750-2659.2010.00195.x

Short, K. R., Kedzierska, K., \& van de Sandt, C. E. (2018). Back to the Future: Lessons Learned From the 1918 Influenza Pandemic. Frontiers in Cellular and Infection Microbiology, 8, 343. https://doi.org/10.3389/fcimb.2018.00343 
Smith, G. J., Vijaykrishna, D., Bahl, J., Lycett, S.J., Worobey, M., Pybus, O. G., Ma, S. K., Cheung, C. L., Raghwani, J., Bhatt, S., Peiris, J. S., Guan, Y., Rambaut, A. (2009). Origins and evolutionary genomics of the 2009 swineorigin H1N1 influenza A epidemic. Nature, 459, 1122e5.

Smith, W., Andrewes, C. H., Laidlaw, P. P. (1933). A virus obtained from influenza patients. Lancet, 2, 66-68.

Sobral, J. M. (2019). Catástrofe e Silêncio: A epidemia da pneumónica em Portugal, no seu tempo e no espaço da recordação. Centenário da Gripe Pneumónica A Pandemia em Retrospetiva, Portugal 1918-1919. Coordenação: Silva H., Pereira R. M., Bandeira F. Multitipo - Artes Gráficas, Lda. Pp. 21-36.

Sobral, J. M., Lima, M. L., Silveira e Sousa, P., \& Castro, P. (2009). Perante a Pneumônica: a epidemia e as respostas das autoridades de saúde pública e dos agentes políticos em Portugal (1918-1919). Dossiê: Influenza Espanhola, Varia História, 25 (42). https://bit.ly/3GRMCX8

Sobral, J. M., \& Lima, M. L. (2018). A epidemia da pneumônica em Portugal no seu tempo histórico. Ler História, (73), 45-66.

Spring H. (2020). Health literacy and COVID-19. Health Information and Libraries Journal, 37, 171-172. https://doi.org/10.1111/hir.12322

Taubenberger, J. K., \& Morens, D. M. (2006). 1918 Influenza: the mother of all pandemics. Emerging infectious diseases, 12(1), 15-22. https://doi.org/bb4v

Taubenberger, J. K., \& Morens, D. M. (2008). The pathology of influenza virus infections. Annual Review of Pathology, 3, 499-522. https://doi.org/cvgs48

Thomas, Y., Boquete-Suter, P., Koch, D., Pittet, D., \& Kaiser, L. (2014). Survival of influenza virus on human fingers. Clinical Microbiology and Infection, 20, O58-O64. https://doi.org/10.1111/1469-0691.12324

Tomkins, S. M. (1992). The influenza epidemic of 1918-19 in Western Samoa. The Journal of Pacific History, 27, 181-197. https://doi.org/c5c3dj

Tsoucalas, G., Karachaliou, F., Kalogirou, V., Gatos, G., Mavrogiannaki, E., Antoniou, A., \& Gatos, K. (2015). The first announcement about the 1918 "Spanish flu" pandemic in Greece through the writings of the pioneer newspaper "Thessalia" almost a century ago. Le Infezioni in Medicina, 23(1), 79-82.

Tumpey, T. M., Basler, C. F., Aguilar, P. V., Zeng, H., Solórzano, A., Swayne, D. E., Cox, N. J., Katz, J. M., Taubenberger, J. K., Palese, P., García-Sastre, A. (2005). Characterization of the reconstructed 1918 Spanish influenza pandemic virus. Science, 310(5745), 77-80.

Vaughan, V. C., \& Palmer, G. T. (1919). Communicable disease in the United States Army during the summer and autumn of 1918. Journal of Laboratory and Clinical Medicine, 4, 647e86. 
Wagner, D. M., Klunk, J., Harbeck, M., Devault, A., Waglechner, N., Sahl, J. W., Enk, J., Birdsell, D. N., Kuch, M., Lumibao, C., Poinar, D., Pearson, T., Fourment, M., Golding, B., Riehm, J. M., Earn, D. J. D., DeWitte, S., Rouillard, J. M., Grupe, G., Wiechmann, I., Bliska, J. B., Keim, P.S., Scholz, H. C., Holmes, E. C., \& Poinar, H. (2014). Yersinia pestis and the Plague of Justinian 541-543 AD: A genomic analysis. The Lancet Infectious Diseases, 14(4), 319-326. https://doi.org/10.1016/S1473-3099(13)70323-2

Wever, P. C., \& van Bergen, L. (2014). Death from 1918 pandemic influenza during the First World War: a perspective from personal and anecdotal evidence. Influenza and Other Respiratory Viruses, 8(5), 538-546. https://doi.org/10.1111/irv.12267

Wilson, N., Oliver, J., Rice, G., Summers, J. A., Baker, M. G., Waller, M., \& Shanks, G. D. (2014). Age-specific mortality during the 1918-19 influenza pandemic and possible relationship to $1889 \mathrm{e} 92$ pandemic. The Journal of Infectious Diseases, 210, 993e5.

World Health Organization. (2020). Ebola Virus Disease.World Health Organization. Acedido a 18 de dezembro de 2021. https://bit.ly/3JrZrck

Zietz, B. P., \& Dunkelberg, H. (2004). The history of the plague and the research on the causative agent Yersinia pestis. International Journal of Hygiene and Environmental Health, 207(2), 165-178. https://doi.org/10.1078/1438-463900259

Zou, X., \& Cao, B. (2020). Battling COVID-19 Using Lessons Learned from 100 Years of Fighting Against Influenza. China CDC Weekly, 2(44), 867-869. https://doi.org/10.46234/ccdcw2020.230 